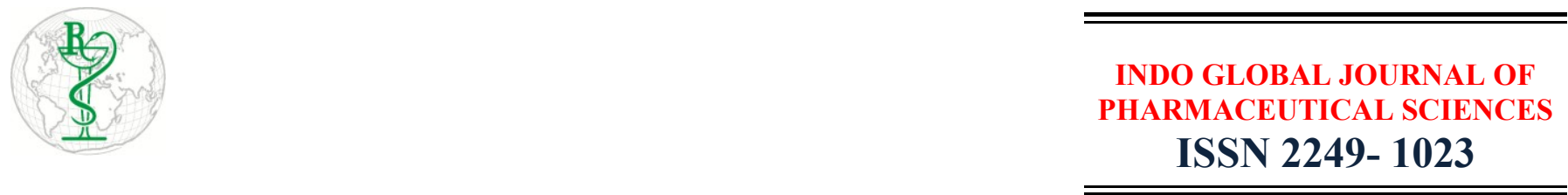

\title{
Biopesticides: A Safe and Ecofriendly Alternative
}

\author{
Pratibha Chauhan *, S Krishna Sundari \\ Department of Biotechnology, Jaypee Institute of Information Technology, Noida \\ Address for Correspondance: Pratibha Chauhan, cpratibha91@gmail.com
}

\begin{abstract}
Keywords
Biopesticides;

Biofertilizers;

Microorganisms;

Chemicals.
\end{abstract}

\begin{abstract}
Biopesticides are natural substances, containing living organisms, their products or byproducts, which help in the management of pests that are injurious to plants. The exploitation of these natural substances in the agricultural sector offers significant advantages as they not only help to maintain food quality and allow for sustainable crop production, but more importantly, they pose minimal risk to the environment. The use of conventional chemical pesticides is known to be associated with several harmful effects as these substances easily vaporize and accumulate in the environment, hence contaminating the air, water and soil. Once accumulated into the environment, chemical pesticides affect non-target species thereby affecting the plants, birds, animals, microbes residing in soil, water bodies and humans leading to chronic health problems such as dementia, birth defects and even cancer. Bio-pesticides in contrast, affect only the specific pest, are effective in very small quantities, reduce the risk of exposure to chemicals, reduce the pollution of air, water and soil, cause less harm to beneficial species and are biodegradable. The most commonly used bio-pesticides are living microorganisms and include- Biofungicides (Trichoderma), Bioinsecticides (Bacillus thuringiensis), Bioherbicides (Phytopthora) and many plant based pesticides such as Neem and Pyrethrin based pesticides. There is thus, a need for substitution of chemical pesticides by biopesticides as the latter play a key role in maintaining productivity and sustainability of the soil, protect the environment from harmful effects of chemical pesticides, and are also an eco-friendly and cost effective input for the farmers. (c) 2016 iGlobal Research and Publishing Foundation. All rights reserved.
\end{abstract}

Conference Proceedings: International Conference on Advances in Plant and Microbial Biotechnology (PMB-2017); JIIT, Noida: February 02-04, 2017

Indo Global Journal of Pharmaceutical Sciences( ISSN 22491023 ; CODEN- IGJPAI; NLM ID: 101610675) indexed and abstracted in EMBASE(Elsevier), SCIRUS(Elsevier),CABI, CAB Abstracts, Chemical Abstract Services(CAS), American Chemical Society(ACS), Index Copernicus, EBSCO, DOAJ, Google Scholar and many more. For further details, visit http://iglobaljournal.com 